An association was found between clinical tenderness and US synovitis of the tibiotalar joint $(p=0.013)$ and the talonavicular joint $(p=0.027)$. No association was noted between clinical swelling and US synovitis in these joints.

No association was noted between clinical and US tenosynovitis of TA ( $p=0.279)$, TP $(p=0.436)$, FB $(p=0.495)$ and FL $(p=0.315)$

Conclusion: Clinical examination of RA ankles may be challenging and needs to be coupled with US, which is more sensitive and accurate in the detection of synovitis and tenosynovitis.

Disclosure of Interests: None declared

DOI: 10.1136/annrheumdis-2021-eular.2720

\section{POS0549 \\ FUNCTIONAL IMPACT OF FOREFOOT INVOLVEMENT IN RHEUMATOID ARTHRITIS}

K. Maatallah ${ }^{1}$, H. Boussaa ${ }^{1}$, H. Riahi ${ }^{2}$, H. Ferjani ${ }^{1}$, W. Triki ${ }^{1}$, M. Habechi ${ }^{1}$, D. Ben Nessib ${ }^{1}$, M. Bouaziz ${ }^{2}$, D. Kaffel ${ }^{1}$, W. Hamdi ${ }^{1}{ }^{1}$ Mohamed Kassab Institute of Orthopedics, Rheumatology, La Manouba, Tunisia; ${ }^{2}$ Mohamed Kassab Institute of Orthopedics, Radiology, La Manouba, Tunisia

Background: Rheumatoid arthritis (RA) is a chronic inflammatory disease that mainly affects small joints of the hands and feet. Foot deformities may affect the patient's gait, thus compromising their daily activities and autonomy.

Objectives: The aim of this study was to analyze its functional impact.

Methods: We conducted a cross-sectional study including patients diagnosed with RA according to the ACR/EULAR 2010 criteria. Demographic variables, Foot Function Index (FFI), and Health Assessment Questionnaire (HAQ) scores were analyzed. We collected data on the following clinical variables: The pain Visual Analog Scale (VAS), forefoot deformities, erythrocyte sedimentation rate (ESR), and Disease Activity Score 28 (DAS28). All patients had feet X-rays and the Larsen score was calculated. A blinded radiologist experienced in musculoskeletal imaging using a Philips HD11 device with a high-frequency linear transducer performed ultrasonography (US) of MTP joints. Synovitis was defined as an abnormal hypoechoic synovial tissue within the capsule that is not displaceable and poorly compressible and that may exhibit Doppler signals. The composite synovitis score (power doppler / grayscale ultrasound (PDUS)) was measured for each joint. The US score of each patient was defined by the sum of the composite scores of the joints studied (0-30). A p-value $<0.05$ was considered significant.

Results: We included 31 patients (25 men and six women) with a mean age of $54.8 \pm 10.8$ years old [32-70]. The mean disease duration was $8.5 \pm 7.2$ years [1-37]. The mean ESR and DAS28 ESR were 33 $\pm 26 \mathrm{~mm}$ [5-102] and $3.8 \pm 1.5$ [0.6-7], respectively. Twenty-nine percent of patients had a high disease activity.

Metatarsalgia was reported by $54.8 \%$ of patients with a mean VAS of $4.5 \pm 3.7$ [0-9]. Forefoot deformities were noted in $42 \%$ of patients: round forefoot in $13 \%$ of cases, triangular forefoot in $29 \%$ of cases, hallux valgus in $29 \%$ of cases, Quintus varus in $29 \%$ of cases, and claw toes in $13 \%$ of cases. Corns and calluses were noted in $42 \%$ and $29 \%$ of cases respectively.

X-rays showed abnormalities in $75 \%$ of patients. The mean Larsen score was $9.8 \pm 6.2[0-28]$.

US showed synovitis in $46.3 \%$ of MTP1, in $53.7 \%$ of MTP2, in $48.3 \%$ of MTP3, in $42.6 \%$ of MTP4, and in $37 \%$ of MTP5 joints. Doppler signal was detected in $5.6 \%$ of MTP1 and MTP2, and in 3.7\% of MTP3, MTP4, and MTP5 joints. The mean US score was $5.3 \pm 4.3[0-15]$.

The mean $\mathrm{FFI}$ was $66.5 \%$. Mean rates of pain, difficulty, and disability were $89.5 \%, 40 \%$, and $70 \%$ respectively. The mean HAQ score was $0.5 \pm 0.5[0-2]$. Severe disability was noted in $20 \%$ of patients.

A significant positive correlation was noted between FFI and, Larsen score $(r=0.214, p=0.014)$ and US score $(r=0.420, p=0.021)$. A significant positive correlation was also noted between HAQ score and, foot pain VAS $(r=0.555, p=0.009)$. Conclusion: Foot involvement is frequently seen in RA. This condition may affect patients' autonomy. Early diagnosis and appropriate treatment are necessary in order to preserve the quality of life.

Disclosure of Interests: None declared

DOI: 10.1136/annrheumdis-2021-eular.2727

\section{POS0550 EVALUATION OF THE INTIMA-MEDIA THICKNESS INDEX BY CAROTID DOPPLER IN PATIENTS WITH RHEUMATOID ARTHRITIS AT HOSPITAL DOCENTE PADRE BILLINI, DOMINICAN REPUBLIC}

T. Polanco Mora ${ }^{1}$, J. Santana Peralta ${ }^{2}$, A. Cornelio ${ }^{1}$, Y. Cruz ${ }^{1}$, E. Rodriguez Bautista ${ }^{1}$, T. Valdez 1 , R. Muñoz ${ }^{1}$, A. Feriz ${ }^{1}{ }^{1}$ Hospital Docente Padre Billini, Reumatologia, Santo Domingo,; ${ }^{2}$ Hospital Docente Padre Billini, Reumatologia, Santo domingo,

Background: Rheumatoid arthritis (RA) is an autoimmune disease systemic affects $0.5-1 \%$ of the world population, predominantly female. ${ }^{(1)}$ Carotid Doppler is used to detect endothelial dysfunction by measuring intima-media thickening flow velocities, subclinical atherosclerosis markers, and vascular tone. ${ }^{(2,3)}$ Measurement of carotid intima-media thickness (cIMT) is useful in assessing cerebrovascular disease and cardiovascular risk in patients with rheumatoid arthritis ${ }^{(4)}$ Intima-media thickness value $>0.9 \mathrm{~mm}$ and presence of plaques Atheromatous cells in the carotid artery are predictive of increased cardiovascular risk and silent heart disease. ${ }^{(5.6)}$

Objectives: To evaluate the carotid intima-media thickness in patients with rheu matoid arthritis

Methods: A prospective, observational, cross-sectional study. Carotid Doppler was performed on outpatient patients with a diagnosis of rheumatoid arthritis from November 2019 to 2020 of the rheumatology service of the Hospital Docente Padre Billini and healthy controls. Inclusion criteria:> 18 years, diagnosis of RA according to ACR / EULAR 2010 classification criteria, carotid Doppler with measurement of the carotid intima-media thickness. Controls without disease, matched by sex and age. The data were analyzed with SPSS V23.

Results: Of 251 patients with a diagnosis of RA, 100 met criteria inclusion, $96.2 \%$ female, 100 healthy controls were included. Average evolution of the disease 7.5 years, 88\%(88) Positive rheumatoid factor, 33\% (33) Positive anti-CCP. 82\% (82) concomitant scDMARD, 70\% (70) bDMARD, 18\% (18) ctDMARD. 53\% (53) Dyslipidemia, 23\% (23) obesity, 10\% (10) hyperglycemia, 8\% (8) smokers. DAS28 showed 57\% (57) low activity, 20\% (20) moderate activity, 15\% (15) remission, $8 \%$ (8) high activity. Carotid Doppler in patients with RA showed $32 \%$ (32) atheromatous plaques, $18.75 \%$ (6) calcified plaques, $1.44 \%$ (1) stenosis bilateral carotid. C-reactive protein and erythrocyte sedimentation rate high $35 \%$ (35) $58 \%$ (58) respectively. Carotid Doppler in healthy controls revealed $17 \%$ (17) atheromatous plaques, $47.05 \%$ (8) calcified plaques. $69 \%$ (69) of RA patients had increased cIMT, mean (SD) cIMT 3.82mm (1.11), controls 58\% (58) increase in cIMT, Mean (SD) $3.12 \mathrm{~mm}(0.93)(p=0.0435)$.

Conclusion: Our study showed that $69 \%$ of patients with Arthritis Rheumatoid featured increased intima-media thickness associated with low DAS28, we recommend assessing cardiovascular risk using carotid Doppler in patients with low to moderate activity. It was observed that in patients with RA and healthy controls more than half present increased carotid intima-media thickness.

\section{REFERENCES:}

[1] JAMA. 2018;320(13):1360-1372.

[2] Villa-Forte, B.F. Mandell / Rev Esp Cardiol. 2011;64(9):809-817.

[3] Meune, C., Touzé, E., Trinquart, L., Allanore, Y. Trends in cardiovascular mortality in patients with rheumatoid arthritis over 50 years: A systematic review and meta-analysis of cohort studies. Rheumatology 2009; 48 (10): 1309-13.

[4] Choi, HK., Rho, Y-H., Zhu, Y., Cea-Soriano, L., Aviña-Zubieta, JA., Zhang Y. The risk of pulmonary embolism and deep vein thrombosis in rheumatoid arthritis: A UK population-based outpatient cohort study. Ann Rheum Dis. 2013; 72 (7): 1182-7.

[5] Gkaliagkousi, E., Gavriilaki, E., Doumas, M., Petidis, K., Aslanidis, S., Stella, D. Cardiovascular risk in rheumatoid arthritis: Pathogenesis, diagnosis, and management. J Clin Rheumatol Pract Rep Rheum Musculoskelet Dis. 2012; 18 (8): 422-30.

[6] Corrales, A., González-Juanatey, C., Peiró, ME., Blanco, R., Llorca, J., González-Gay, MA. Carotid ultrasound is useful for the cardiovascular risk stratification of patients with rheumatoid arthritis: Results of a population-based study. Ann Rheum Dis. 2013.

Disclosure of Interests: None declared

DOI: 10.1136/annrheumdis-2021-eular.2743 